\title{
Synthesis and characterization of magnetite/hydroxyapatite tubes using natural template for biomedical applications
}

\author{
M SNEHA, N MEENAKSHI SUNDARAM* and A KANDASWAMY \\ Department of Biomedical Engineering, PSG College of Technology, Coimbatore 641004, Tamil Nadu, India
}

MS received 29 September 2015; accepted 29 October 2015

\begin{abstract}
Inorganic nanotubes have attracted much attention during the last few decades for its potential applications in the field of regenerative medicine and controlled drug delivery. In the present work, we have designed and synthesized magnetite hydroxyapatite micro and nanotubes. The first step is the formation of magnetite $\left(\mathrm{Fe}_{3} \mathrm{O}_{4}\right)$ tubes on natural template followed by hydroxyapatite (HAp) bioceramic coated on the $\mathrm{Fe}_{3} \mathrm{O}_{4}$ tubes. HAp improves the biocompatibility and stability of the prepared tubes. Sintering at $900^{\circ} \mathrm{C}$ improves the crystalline stability of nanotubes and removes the natural template. $X$-ray diffraction, $\mathrm{N}_{2}$ adsorption-desorption studies (BET), thermogravimetric analysis, differential scanning calorimetry, optical micrographs, field emission scanning electron microscope and transmission electron microscope studies were carried out to confirm the structural and morphological analysis of prepared magnetic tubular structure.
\end{abstract}

Keywords. Magnetite; hydroxyapatite; hyperthermia; tubular structure; transmission electron microscope.

\section{Introduction}

Nanotechnology has become a promising and multifaceted platform for the discovery of novel materials with improved properties and applications in cancer treatment. Nanomaterials have extremely good potential for early detection, diagnosis and treatment of cancer [1]. The advantages of nanoparticle-based drug delivery system include reduced side effects, longer circular time and improved pharmacokinetics [2-4]. Cancer is a most dreadful disease and is still not easily treated by conventional therapies. Hyperthermia is the delivery of heat to the tumour cells. It is used in combination with other modalities of treatment, such as radiotherapy, chemotherapy and surgery [5].

When superparamagnetic nanoparticles are subjected to an AC magnetic field, it shows extraordinary heating effects due to the magnetization reversal process of the particles (such as Neel and Brownian relaxation process). In magnetically mediated hyperthermia, the magnetic nanoparticles are targeted towards the tumour site and heated using an external alternating magnetic field in the range of $0-15 \mathrm{kA} \mathrm{m}^{-1}$ at a frequency of $100 \mathrm{kHz}$ [6,7]. Superparamagnetic iron oxide nanoparticles, especially magnetite phase $\left(\mathrm{Fe}_{3} \mathrm{O}_{4}\right)$, are widely used for imaging and therapeutic applications as they are capable of non-invasive detection and treatment of tumours. When they are used in conjugation or loaded with tumour-specific targeting ligands, these nanoparticles have the ability to deliver the anti-cancer drugs specifically to tumours and, therefore, the side effects can be minimized on the normal cells [8-10]. The magnetic nanotubes must be

\footnotetext{
*Author for correspondence (nmsundaram75@gmail.com)
}

coated with a biocompatible material to improve its stability and biocompatibility [11]. The calcium phosphate-based bioceramics such as hydroxyapatite (HAp) plays a vital role in biomedical applications due to its excellent properties like bioactivity, osteoconductivity and biocompatibility [12]. HAp is predominantly used in nanomedicine for applications in bone reconstruction and cancer treatment [13]. The effect of magnetic field on the orientation of HAp nanocrystals in a magnetic field under physiological conditions shows magnetic control over the biomaterials response [14].

Synthesis of nanotubes from inorganic materials has also attracted attention due to its unique applications in the areas such as sensing, catalysis and electronics [15]. The double end opened tubular nanostructures are ideal for drug loading and delivery applications in a controlled mechanism. Nanotubes have been synthesized from a variety of inorganic materials such as $\mathrm{SiO}_{2}$ [16], $\mathrm{TiO}_{2}$ [17], $\mathrm{Al}_{2} \mathrm{O}_{3}$ [18], CdSe [19], $\mathrm{ZnS}$ [20], $\mathrm{Au}$ [21], Co and Fe [22].

According to Chandanshive et al [23] HAp nanotubes synthesis involves a sol-gel process under neutral conditions in the presence of a sacrificial anodic alumina template. The diameter of the resulting tubes was in the range of 14-350 $\mathrm{nm}$ [23]. Lee et al [24] synthesized iron oxide nanotubes by prolonged sintering of iron oxide nanoparticles during chemical vapour condensation at $800^{\circ} \mathrm{C}$ for $6 \mathrm{~h}$ [24]. Singh et al [11] prepared poly (caprolactone)-based magnetic hydroxyapatite nanotubes (MHAnt). A hollow tube of HA-MNPs was created, in which HA formed an outer shell and most of the MNPs lined the inner shell surface [11].

In this work, we have developed $\mathrm{HAp}$-coated $\mathrm{Fe}_{3} \mathrm{O}_{4}$ nanotubes by Ceiba pentandra as templates. The coating of HAp onto the $\mathrm{Fe}_{3} \mathrm{O}_{4}$ core structure has been confirmed by field 
emission scanning electron microscope (FE-SEM), transmission electron microscope (TEM) and selected area electron diffraction (SAED) patterns. So, cancer drug-loaded HApcoated magnetite tubular structure is an ideal applicant for magnetic hyperthermia, especially in bone cancer (osteosarcoma) treatment. So far, there is no work on natural template HAp-coated magnetite $\left(\mathrm{Fe}_{3} \mathrm{O}_{4}\right)$ tubular structure.

\section{Materials and methods}

\subsection{Kapok fibre}

Kapok fibres (figure 1) were isolated from its seeds and washed with distilled water and ethanol to remove the impurities.

\subsection{Preparation of iron oxide tubular structure}

Kapok fibres were immersed in ferric chloride solution $\left(0.25 \mathrm{~mol} \mathrm{l}^{-1}\right)$ for $1 \mathrm{~h}$. Ferrous chloride solution $\left(0.125 \mathrm{~mol} \mathrm{l}^{-1}\right)$ was then added to the above solution under constant stirring for $1 \mathrm{~h}$. $\mathrm{pH}$ was adjusted to 12 by using sodium hydroxide $\left(1 \mathrm{~mol}^{-1}\right)$. The entire solution was maintained at $70^{\circ} \mathrm{C}$ for $1 \mathrm{~h}$. It was washed several times with distilled water to remove any impurities present and finally dried.

\subsection{Preparation of HAp tubular structure}

Kapok fibres were immersed in calcium nitrate solution $\left(1 \mathrm{~mol}^{-1}\right)$ for $1 \mathrm{~h}$. Diammonium hydrogen phosphate solution $\left(0.6 \mathrm{~mol}^{-1}\right)$ was then added to the above solution under constant stirring for $1 \mathrm{~h}$. $\mathrm{pH}$ was adjusted to 10 by using ammonia solution. The entire solution was maintained at $70^{\circ} \mathrm{C}$ for $1 \mathrm{~h}$. It was washed several times with distilled water to remove any impurities present and finally dried.

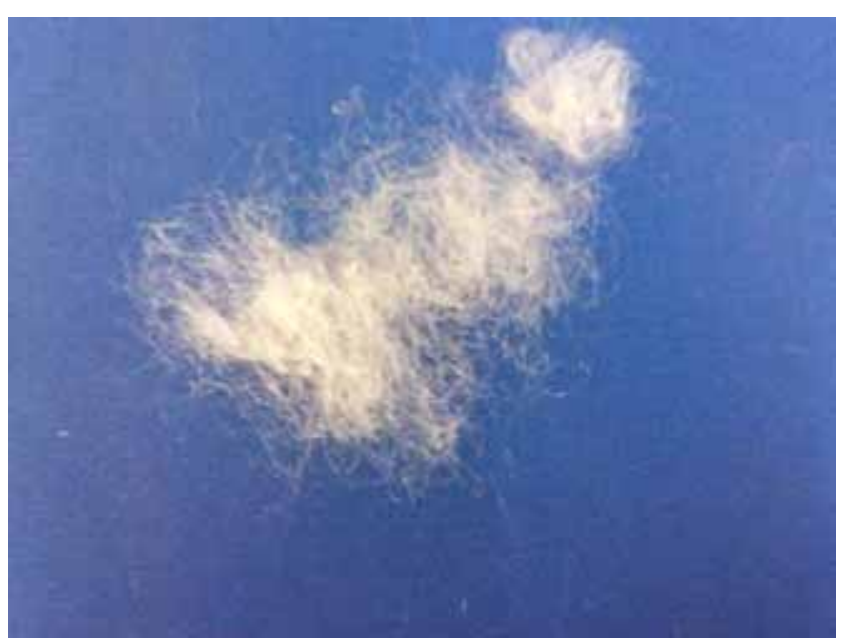

Figure 1. Kapok fibres.

\subsection{Preparation of HAp-coated iron oxide tubular structure}

The $\mathrm{Fe}_{3} \mathrm{O}_{4}$ loaded fibres were dispersed in calcium nitrate solution $\left(1 \mathrm{~mol} \mathrm{l}^{-1}\right)$ under stirring for $1 \mathrm{~h}$. Diammonium hydrogen phosphate $\left(0.6 \mathrm{~mol} \mathrm{l}^{-1}\right)$ was added to the above solution under stirring for $1 \mathrm{~h}$. Ammonia solution was used to adjust the $\mathrm{pH}$ value between 8 and 10 . The solution was kept for ageing for $24 \mathrm{~h}$ and washed with distilled water. It was then dried at $70^{\circ} \mathrm{C}$ overnight. The dried sample was sintered at $900^{\circ} \mathrm{C}$ for $2 \mathrm{~h}$ and stored in an airtight container for further analysis.

\subsection{Preparation of iron oxide coated on HAp tubular structure}

The HAp loaded fibres were dispersed in ferric chloride solution $\left(0.25 \mathrm{~mol} \mathrm{l}^{-1}\right)$ under stirring for $1 \mathrm{~h}$. Ferrous chloride solution $\left(0.125 \mathrm{~mol} \mathrm{l}^{-1}\right)$ was added to the above solution under stirring for $1 \mathrm{~h}$. Sodium hydroxide solution was used to adjust the $\mathrm{pH}$ to 12 . The solution was kept for ageing for $24 \mathrm{~h}$ and washed with distilled water. It was then dried at $70^{\circ} \mathrm{C}$ overnight. The dried sample was sintered at $900^{\circ} \mathrm{C}$ for $2 \mathrm{~h}$ and stored in an airtight container for further analysis.

\section{Characterization}

\subsection{Powder X-ray diffractometer}

Figure 2 shows the X-ray diffraction (XRD) patterns of the (a) pure iron oxide, (b) pure HAp, (c) iron oxide-coated HAp and (d) HAp-coated iron oxide. The characteristic peaks in the pattern of iron oxide agree well with the standard

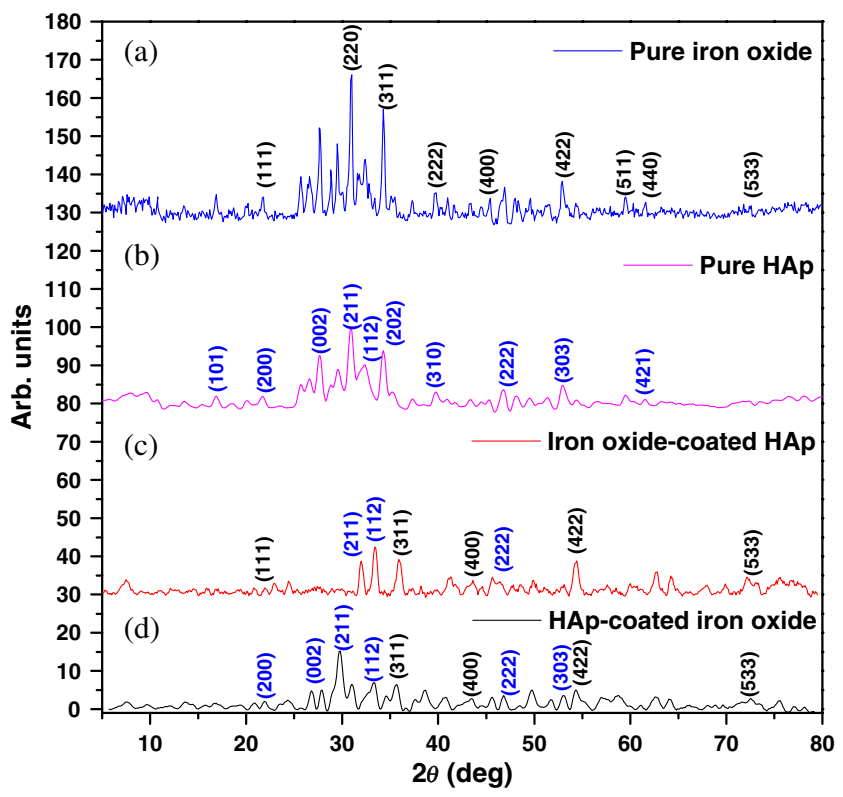

Figure 2. X-ray diffraction patterns of the (a) pure iron oxide, (b) pure HAp, (c) iron oxide-coated HAp and (d) HAp-coated iron oxide. 
JCPDS pattern of (19-0629). The XRD patterns of the powder obtained were in good agreement with the XRD patterns of an HAp standard available in JCPDS (09-0432). The HAp coated with iron oxide exhibits a mixed phase of both HAp and iron oxide and vice versa.

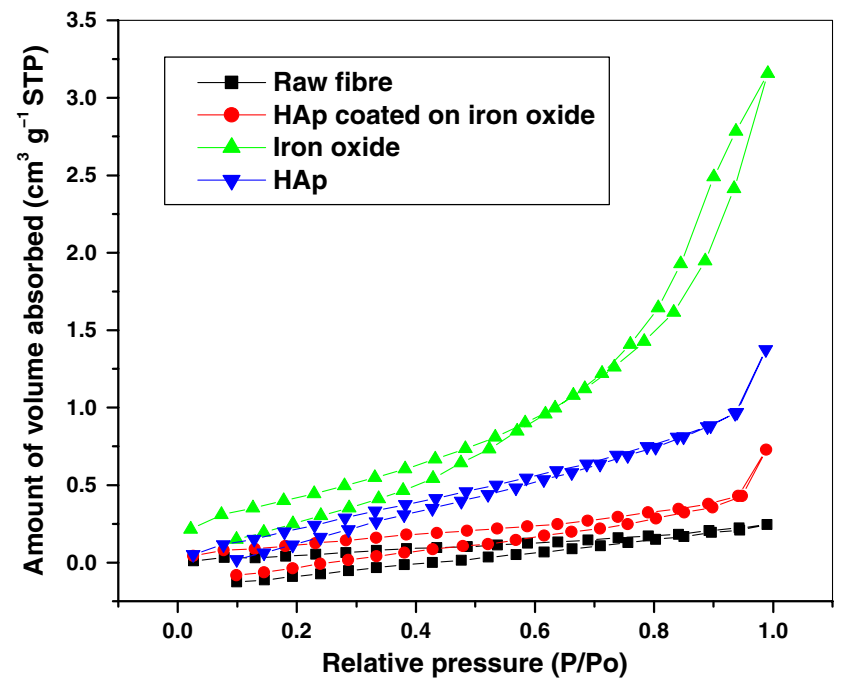

Figure 3. $\mathrm{N}_{2}$ adsorption-desorption studies of raw fibre, iron oxide, HAp and HAp coated on iron oxide.

Table 1. Surface characteristics of prepared samples.

\begin{tabular}{lclc}
\hline & $\begin{array}{c}\text { Surface } \\
\text { area }\left(\mathrm{m}^{2} \mathrm{~g}^{-1}\right)\end{array}$ & $\begin{array}{c}\text { Pore volume } \\
\left(\mathrm{cc} \mathrm{g}^{-1}\right)\end{array}$ & Pore size $(\mathrm{nm})$ \\
\hline HAp & 5.185 & 0.006159 & 7.447 \\
Iron oxide & 75.082 & 0.1839 & 6.231 \\
$\begin{array}{l}\text { HAp-coated } \\
\text { iron oxide }\end{array}$ & 6.623 & 0.0126 & 6.318 \\
Raw fibre & 9.697 & 0.008953 & 6.330 \\
\hline
\end{tabular}

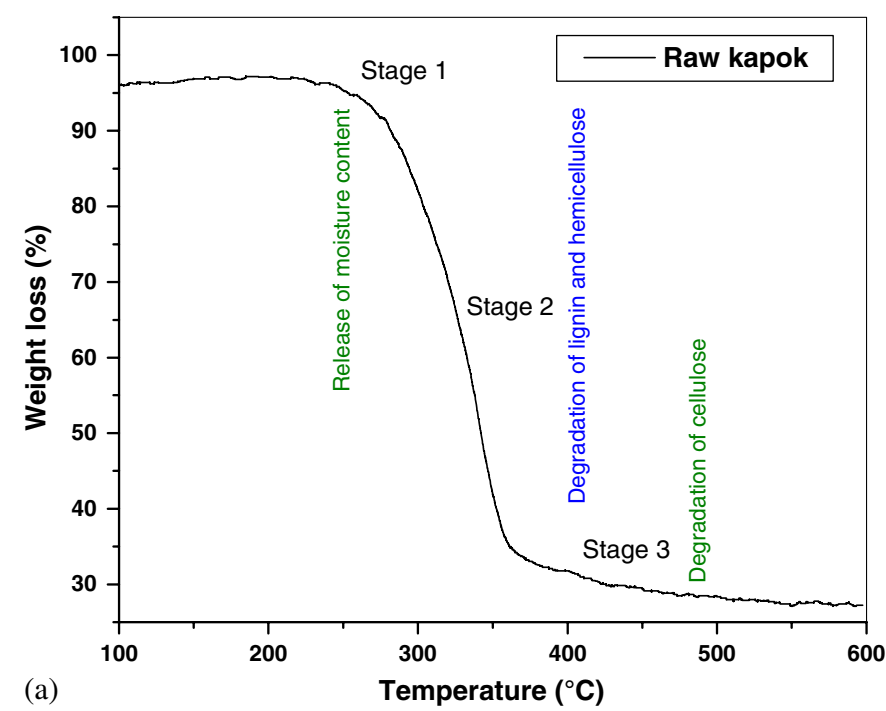

\section{$3.2 \mathrm{~N}_{2}$ adsorption-desorption studies (BET)}

The nitrogen adsorption and desorption isotherm of synthesized HAp-coated iron oxide is shown in figure 3. In this study, we have observed that the synthesized material has less surface area and irregular isotherm curve. Small surface area indicates that the material has a large amount of aggregation during the calcinations process. The surface area, pore volume, pore size are mentioned in table 1 .

\subsection{Thermogravimetric analysis}

Thermal stability of raw kapok fibres and iron oxide/HAp fibres was obtained by using TA Q500 with a heating rate of $20^{\circ} \mathrm{C} \mathrm{min}{ }^{-1}$, from 100 to $600^{\circ} \mathrm{C}$ in a nitrogen atmosphere. Thermogravimetric analysis (TGA) was used to measure the weight loss of fibres as a function of rising temperature.

In figure $4 \mathrm{a}$, the first stage of weight loss was observed between 100 and $269^{\circ} \mathrm{C}$, which corresponds to the release of moisture content from the fibre. The second stage of weight loss occurred between the temperature 270 and $361^{\circ} \mathrm{C}$, which is due to the degradation of lignin and hemicellulose. The third stage of weight loss occurred between the temperature 362 and $510^{\circ} \mathrm{C}$, due to degradation of cellulose and other cellulosic matters from the fibre.

In figure $4 \mathrm{~b}$ (before sintering), the first stage of weight loss was observed between 100 and $160^{\circ} \mathrm{C}$, which is due to the vapourization of adsorbed water. The second stage of weight loss occurred between the temperature 161 and $311^{\circ} \mathrm{C}$, due to crystallization of HAp. The third stage of weight loss occurred between the temperature 312 and $761^{\circ} \mathrm{C}$, due to the breakage of $\mathrm{CO}_{3}^{2-}$ and $\mathrm{HPO}_{4}$.

\subsection{Differential scanning calorimetry}

Kapok fibre shows a small exothermic peak at $340^{\circ} \mathrm{C}$ and minor endothermic peak around $370^{\circ} \mathrm{C}$ (figure $5 \mathrm{a}$ ). In

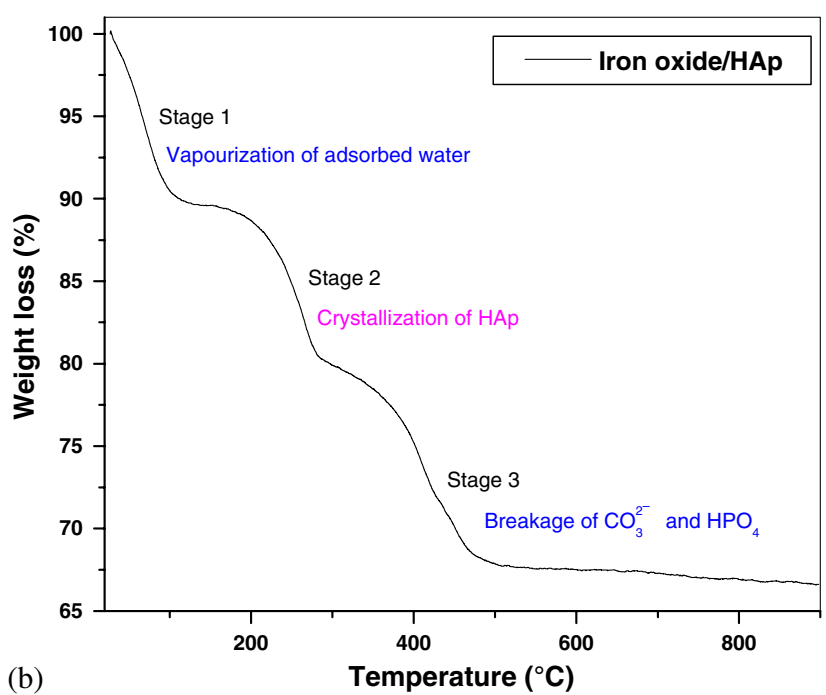

Figure 4. (a) TGA of raw kapok fibre and (b) TGA of iron oxide/HAp. 
differential scanning calorimetry (DSC), a strong endothermic peak was observed between 95 and $100^{\circ} \mathrm{C}$. This is due to the removal of the solvent molecule. Two slight endothermic peaks were observed at 290 and $430^{\circ} \mathrm{C}$. The second peak is due to crystallization process. Another slight endothermic peak was observed at $520^{\circ} \mathrm{C}$. This is due to magnetite phase crystallization (figure $5 \mathrm{~b}$ ).

\subsection{Optical micrographs}

Figure 6a presents optical microscope images of raw kapok fibres and its cross-sectional image. In our experiment,

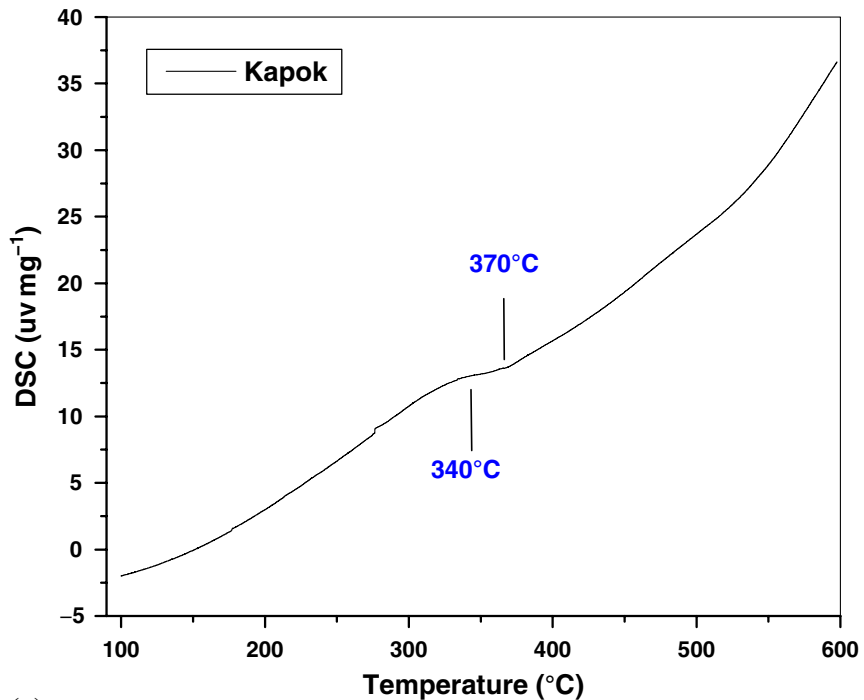

(a)

Temperature $\left({ }^{\circ} \mathrm{C}\right)$

Figure 5. (a) DSC of raw kapok fibre and (b) iron oxide/HAp. we coated iron oxide nanoparticle on kapok fibre. The microscope image reveals the fine structural features of the material surfaces. The iron oxide nanoparticles have coated $70 \%$ on the fibre template and nanoparticle aggregation on the sides of the tubes can be seen from figure $6 b$. The nanoparticles are deposited only on the outer surface of the fibre template; surprisingly, the nanoparticles did not spread through the surfaces inside the fibre. Uniform deposition of HAp nanoparticles on the fibre template can be seen from figure $6 \mathrm{c}$. The cross-sectional view of HAp showed a tubular structure with nanometre-sized diameters. It has unique properties that can be exploited in the

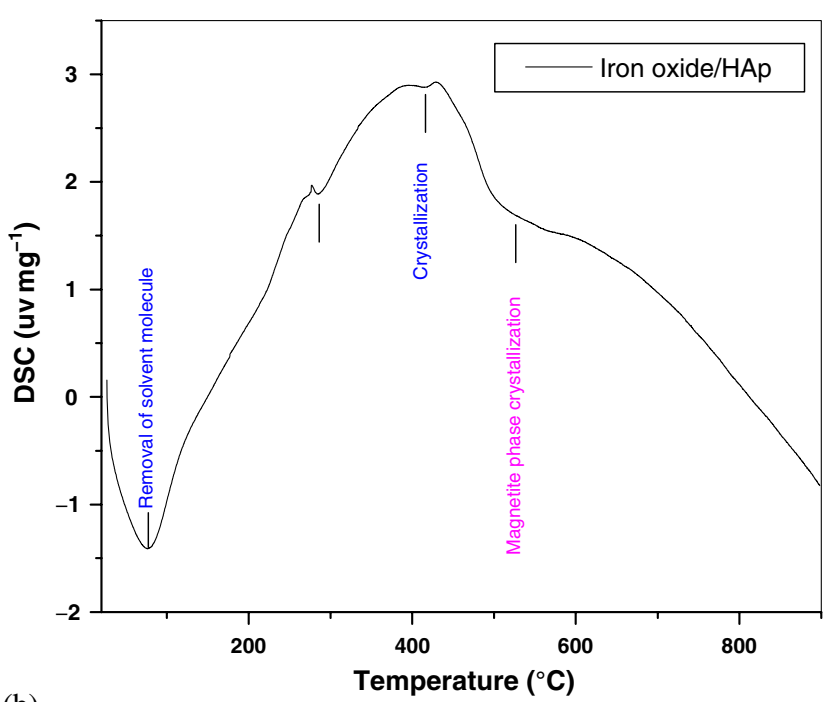

(b)

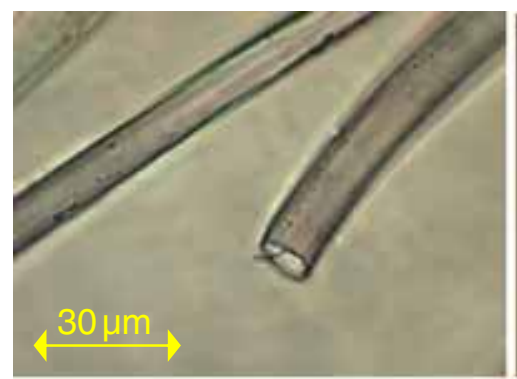

(a)

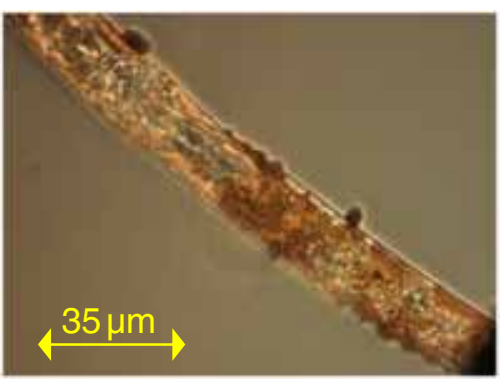

(b)

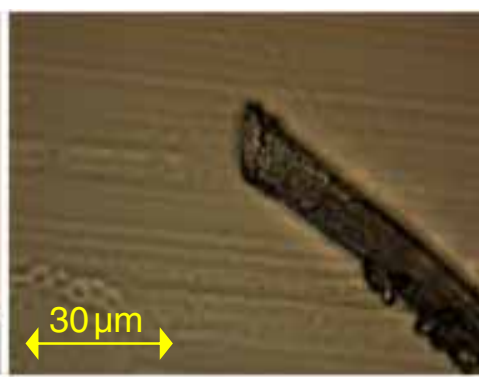

(c)

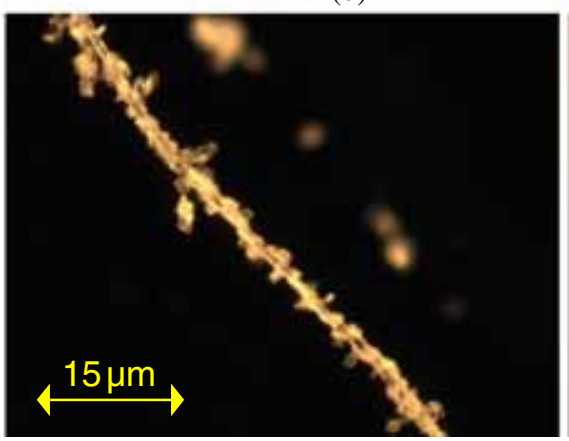

(d)

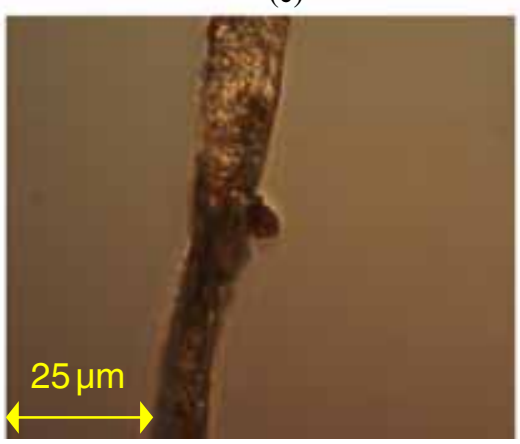

(e)

Figure 6. Optical micrograph of (a) kapok fibre, (b) iron oxide nanoparticle, (c) hydroxyapatite nanoparticles, (d) HAp coating on iron oxide tube and (e) iron oxide coating on HAp tube. 

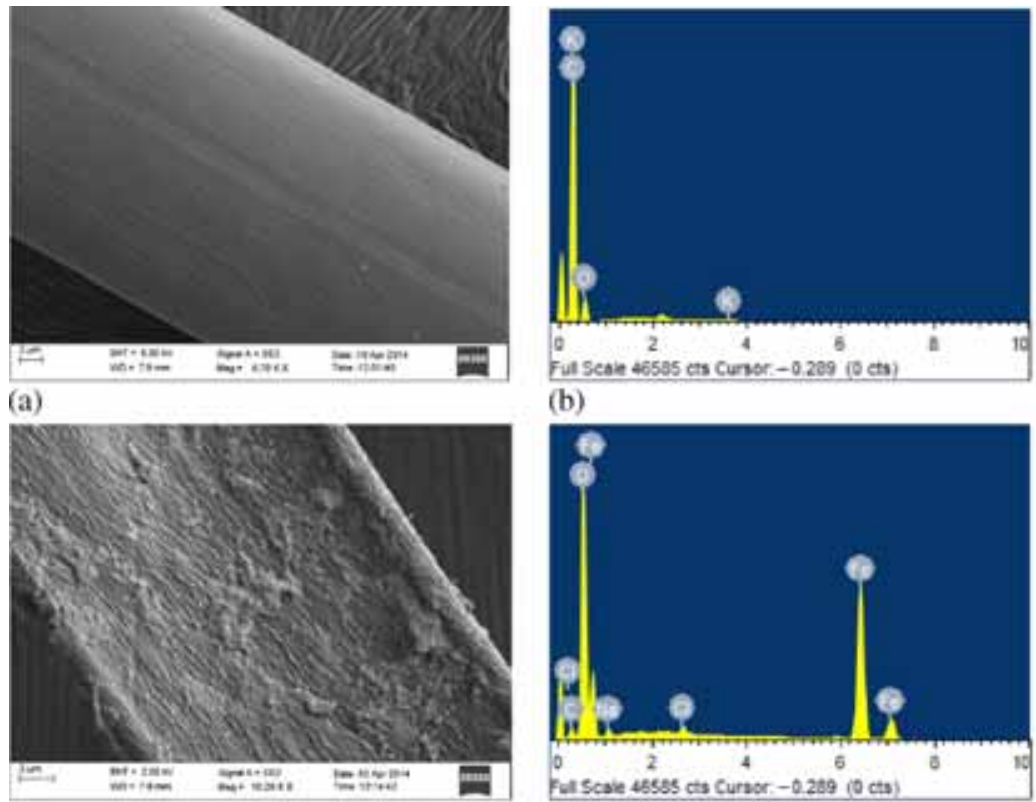

(b)
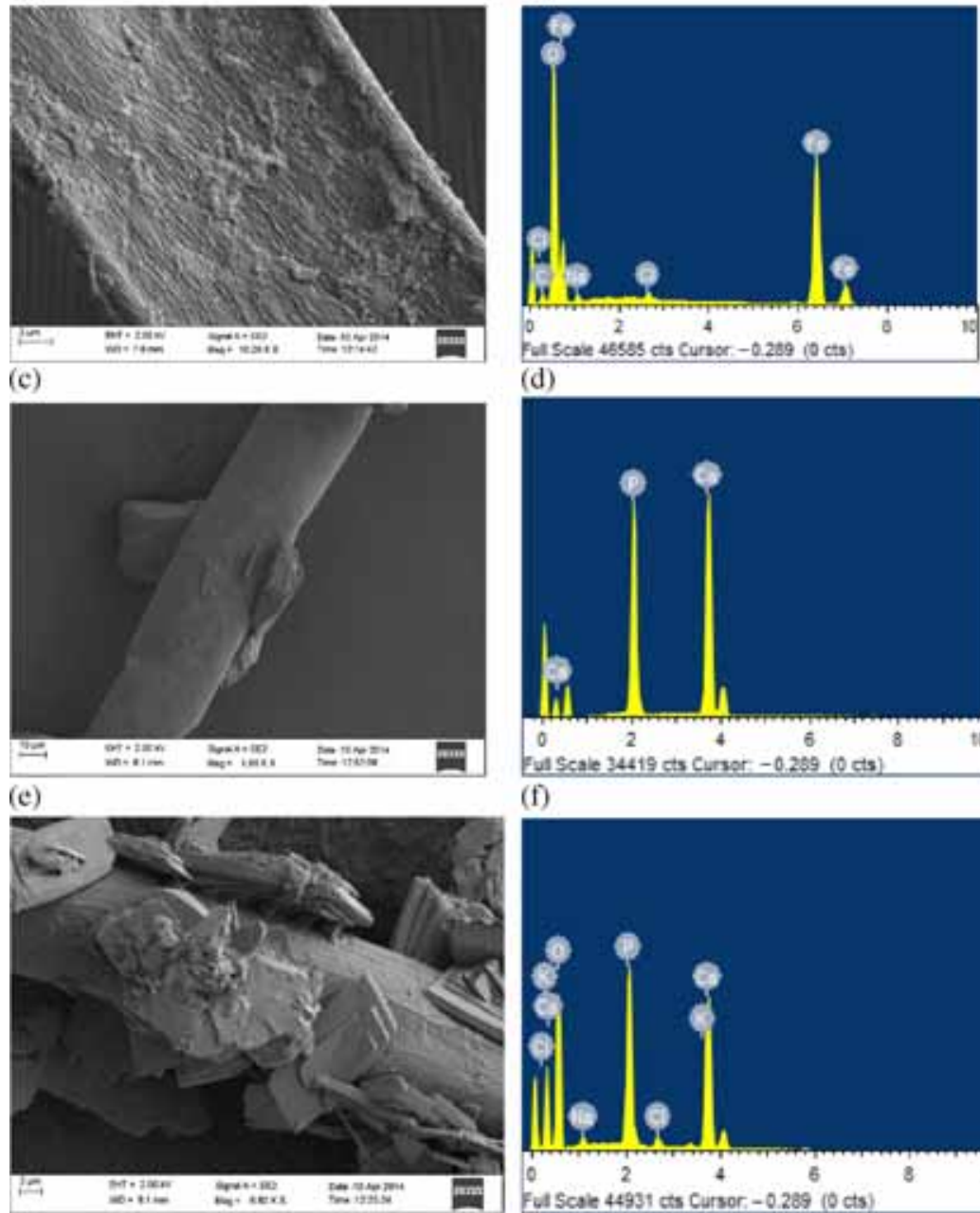

(d)
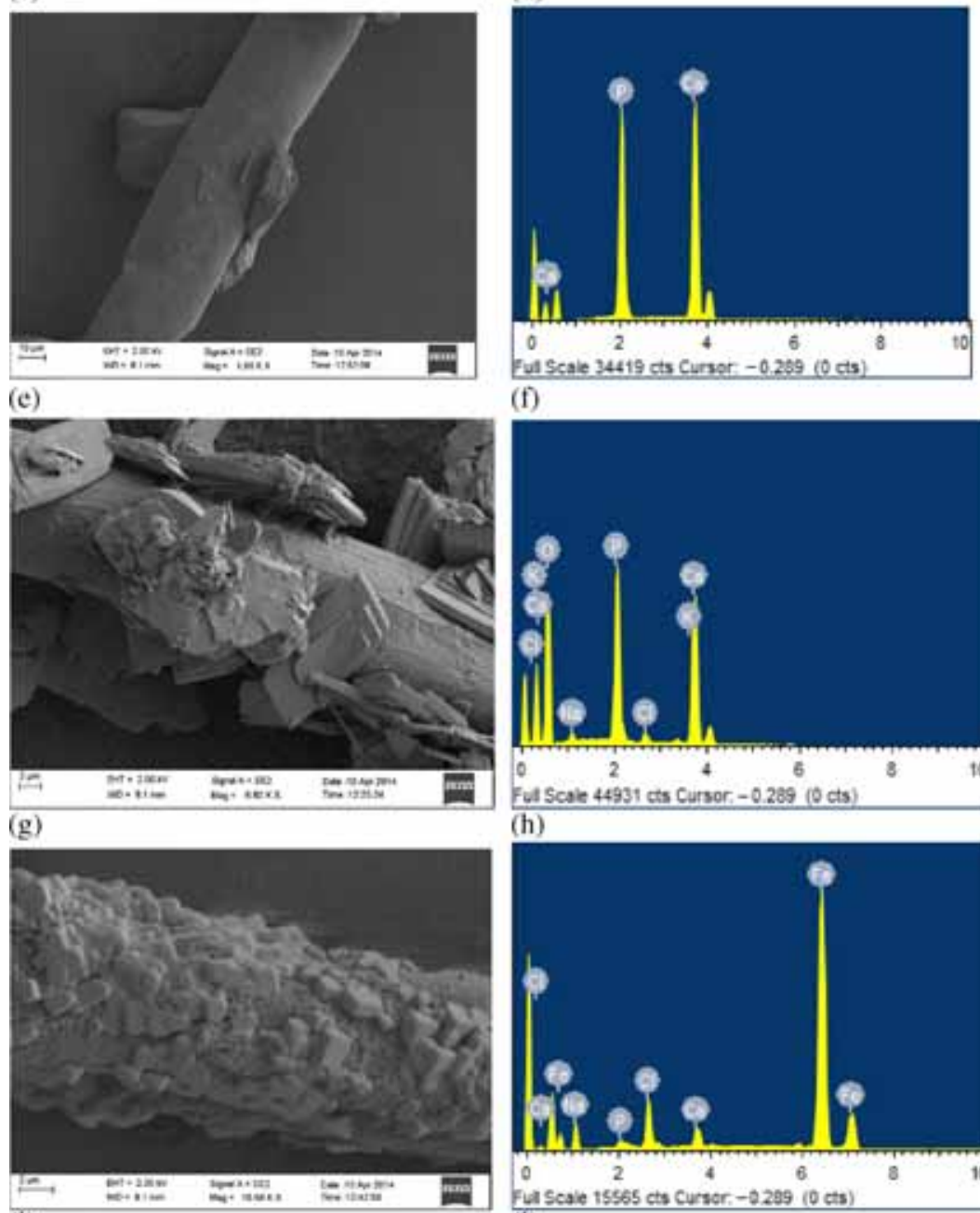

(f)

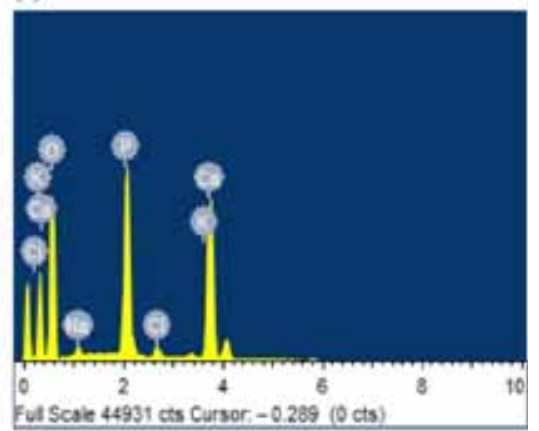

(h)

(i)

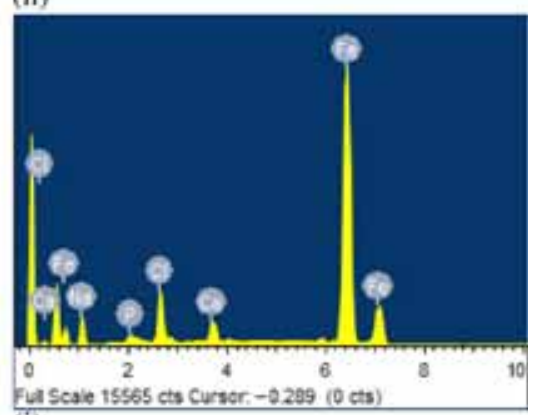

(j)

Figure 7. (a) FE-SEM image, (b) EDAX of raw kapok fibre, (c, d) iron oxide nanoparticles coated on kapok fibre and its $\operatorname{EDAX},(\mathbf{e}, \mathbf{f})$ hydroxyapatite nanoparticles coated on kapok fibre and its $\operatorname{EDAX},(\mathbf{g}, \mathbf{h})$ hydroxyapatite nanoparticles coated on iron oxide-kapok fibre and its EDAX and $(\mathbf{i}, \mathbf{j})$ iron oxide nanoparticles coated on hydroxyapatite-kapok fibre and its EDAX. 
diagnosis and treatment of cancer. In figure $6 \mathrm{~d}$, the coating of HAp nanoparticles on iron oxide-kapok template can be visualized clearly under the optical microscope. The HAp is deposited uniformly on the template, and this condition is highly suited for hyperthermia and drug delivery apllications. The deposition of iron oxide nanoparticles on HAp-kapok template can be seen clearly in figure 6e. The smooth and ordered coating on nanoparticles is essential in biomedical applications.

\section{$3.6 \quad F E-S E M$ (with template)}

A silky appearance and smooth surface can be seen for raw kapok fibre in figure 7a. By the microscope observation, kapok fibres are transparent with characteristic air bubbles in the lumen. Kapok fibres are 10-35 mm long, with a diameter of 20-43 $\mu \mathrm{m}$. The EDAX analysis shows that the pure kapok fibre consists of carbon and oxygen due to its pure cellulose structure. In figure $7 \mathrm{c}$, the deposition of iron

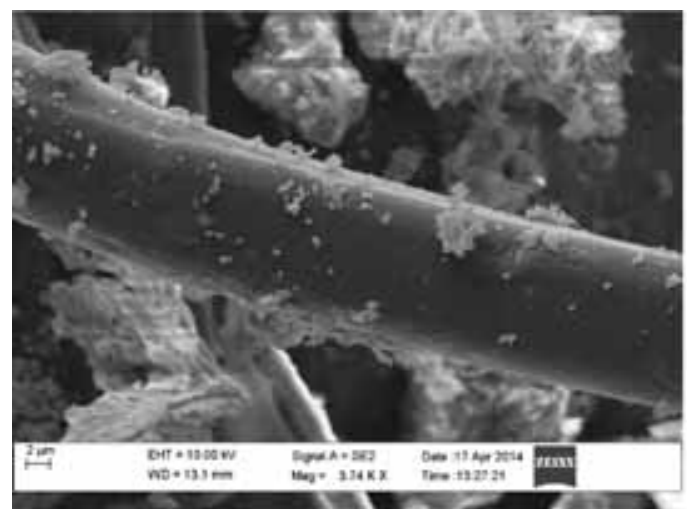

(a)

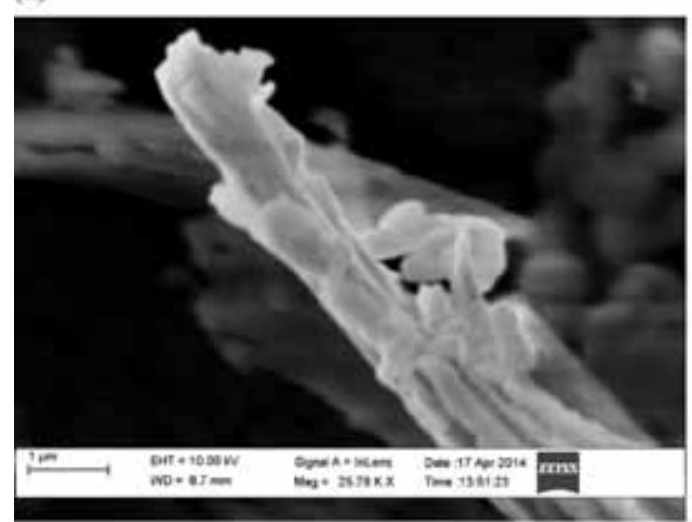

(c)

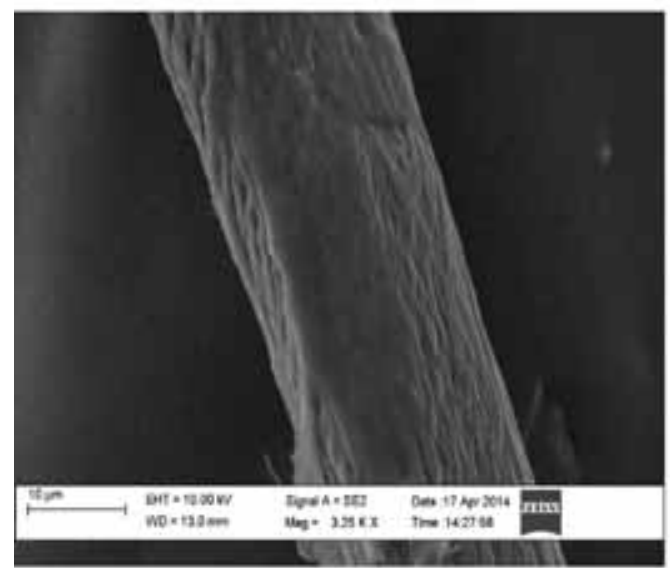

(e)

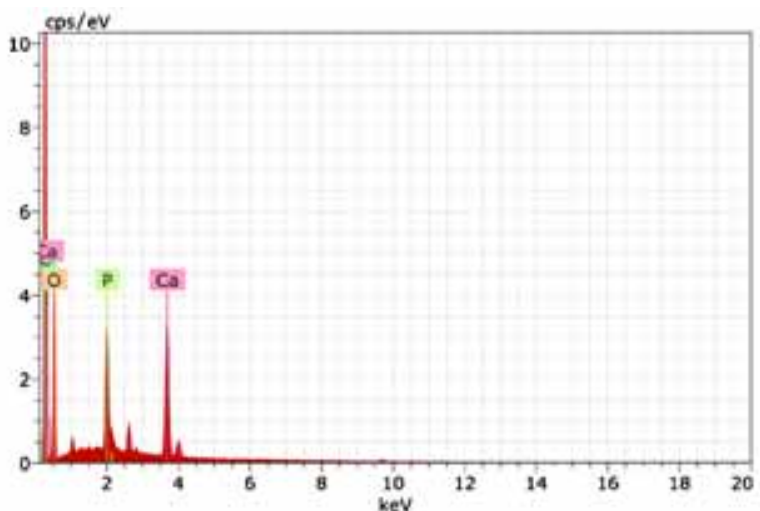

(b)

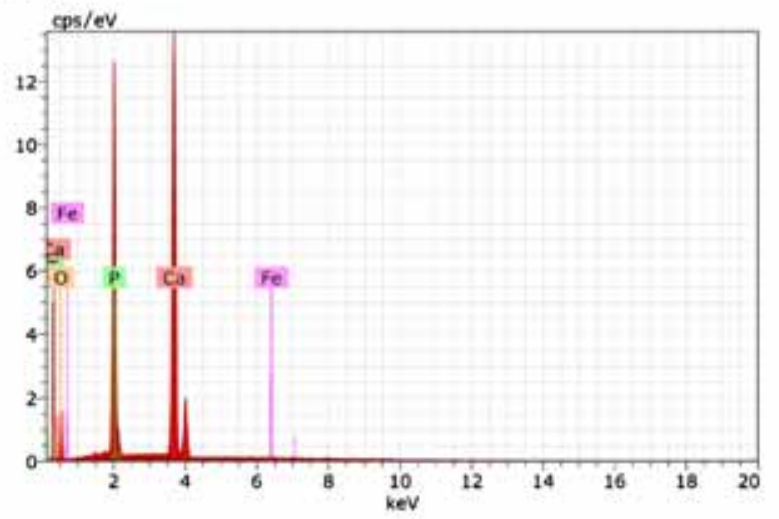

(d)

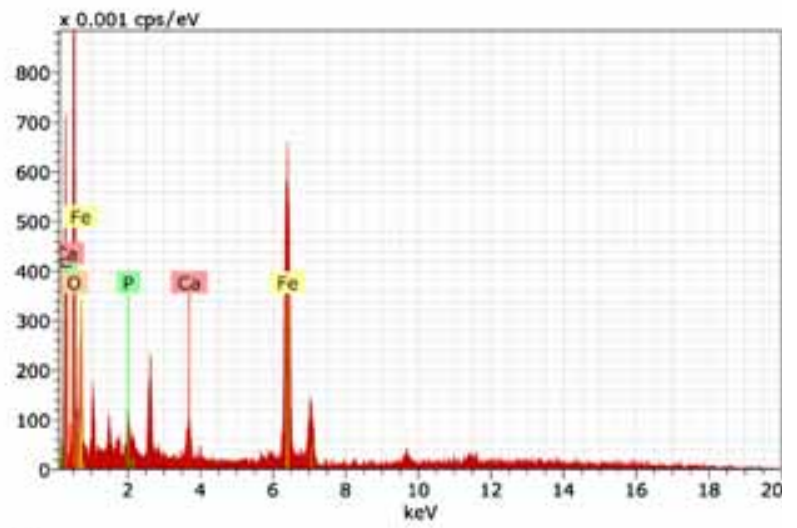

(f)

Figure 8. (a, b) FE-SEM images of HAp tubes and its EDAX, (c, d) HAp nanoparticles coated on iron oxide and its EDAX and $(\mathbf{e}, \mathbf{f})$ iron oxide nanoparticles coated on HAp and its EDAX. 
oxide nanoparticles on kapok fibre can be visualized under FE-SEM. The air entrapment inside the fibre disappeared after coating with iron oxide nanoparticle. The structure became completely flattened. The overall tubular structure was retained and unbroken. The surface of the fibres was also rougher. The uniform coating of HAp nanoparticles on the fibre surface can be visualized and in addition to the coating, HAp aggregates also attached to the surface which is seen in figure 7e. This may be due to longer exposure of nanoparticles to the template. The HAp is well coated on iron oxidekapok fibre, as seen in figure $7 \mathrm{~g}$. In figure $7 \mathrm{i}$, a continous coating of iron oxide nanoparticles on HAp-kapok fibre can be seen under FE-SEM analysis.

Calcination: These samples were calcined to remove the kapok fibre templates. The calcination temperature for iron oxide and HAp tubes is $900^{\circ} \mathrm{C}$ for $2 \mathrm{~h}$.

\subsection{FE-SEM (after removal of template)}

The micromorphology and surface analysis of the prepared sample are carried out by field emission scanning electron microscope, which is shown in figure 8. Figure 8a shows the pure HAp nanotubes formed on the kapok fibre. It has an uniform and smooth surface. Several millimetres long tubular structures are formed even after the removal of the kapok template. The EDAX analysis shows that the formed composition was calcium-rich $\mathrm{HAp}$ with a $\mathrm{Ca} / \mathrm{P}$ ratio of 1.7928 . Figure $8 \mathrm{c}$ shows the $\mathrm{HAp}$-coated $\mathrm{Fe}_{3} \mathrm{O}_{4}$ nanotubular structure. Several tubular-like structures are observed after the sintering process. The EDAX analysis exihibits the presence of $\mathrm{Fe}_{3} \mathrm{O}_{4}$ in the inner core and stochiometric formation of HAp with $\mathrm{Ca} / \mathrm{P}$ ratio of 1.682 on the outer core. Since $\mathrm{Fe}_{3} \mathrm{O}_{4}$ is well buried inside, poor iron signals are identified. Iron oxide nanoparticles coated on HAp is shown in figure 8e.

\subsection{Transmission electron microscope}

3.8a Iron oxide tubular structure: Figure 9 represents the TEM image of synthesized magnetite tubular structure, with the length of 100-110 nm.

3.8b HAp tubular structure: The TEM image of HAp tubular structure is shown in figure 10, in which the
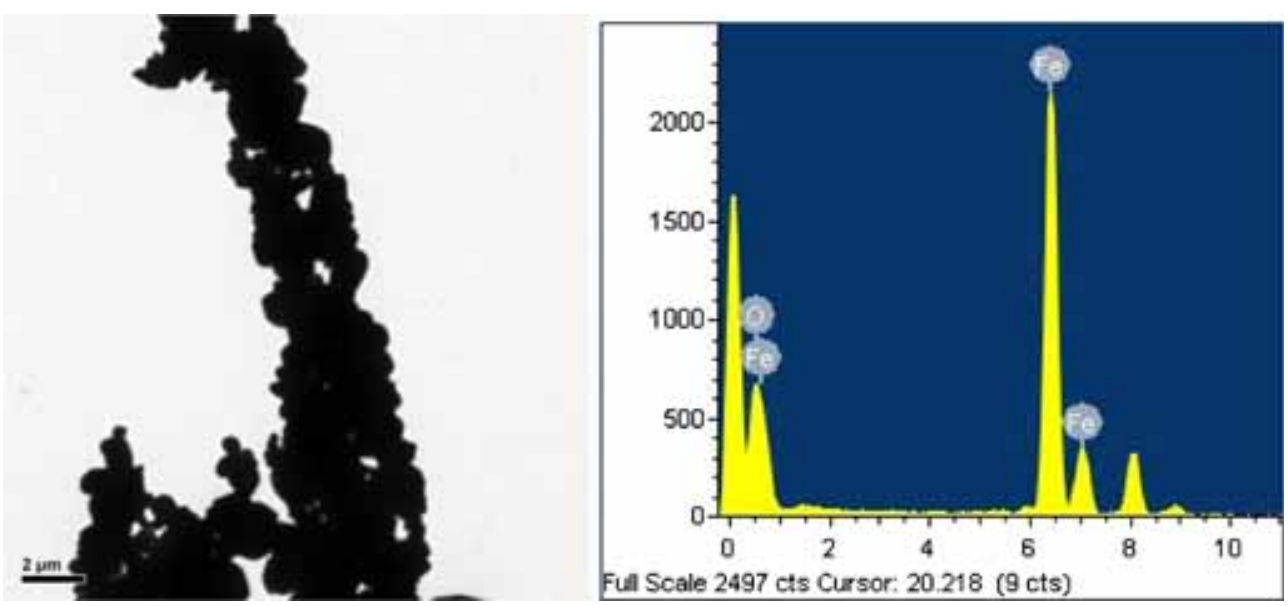

Figure 9. Iron oxide tubular structure.
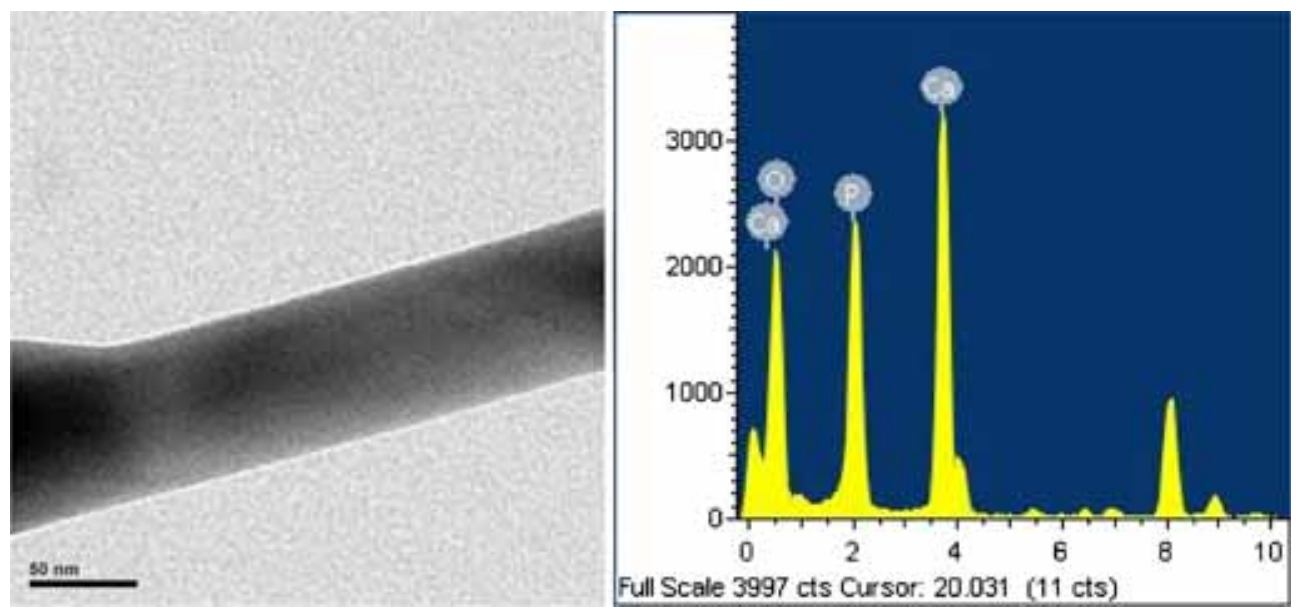

Figure 10. HAp tubular structure. 


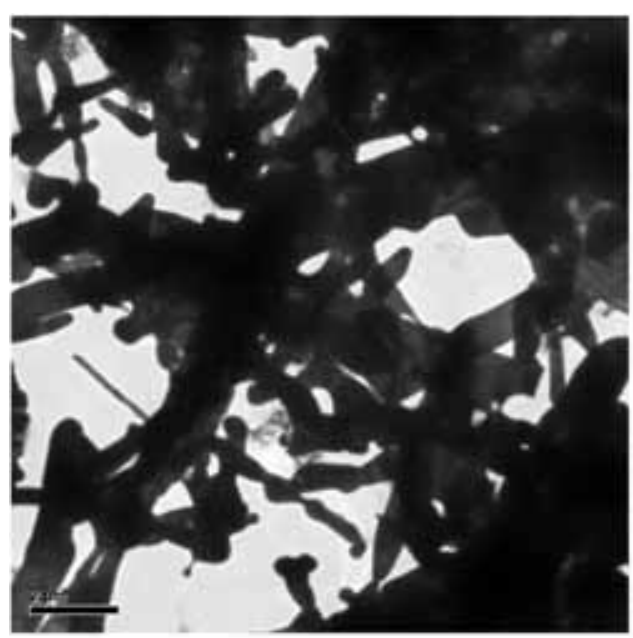

(a)

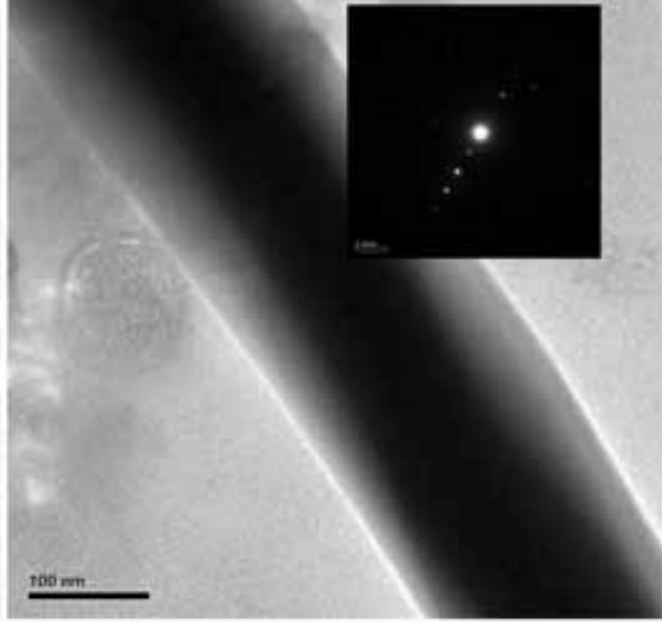

(b)

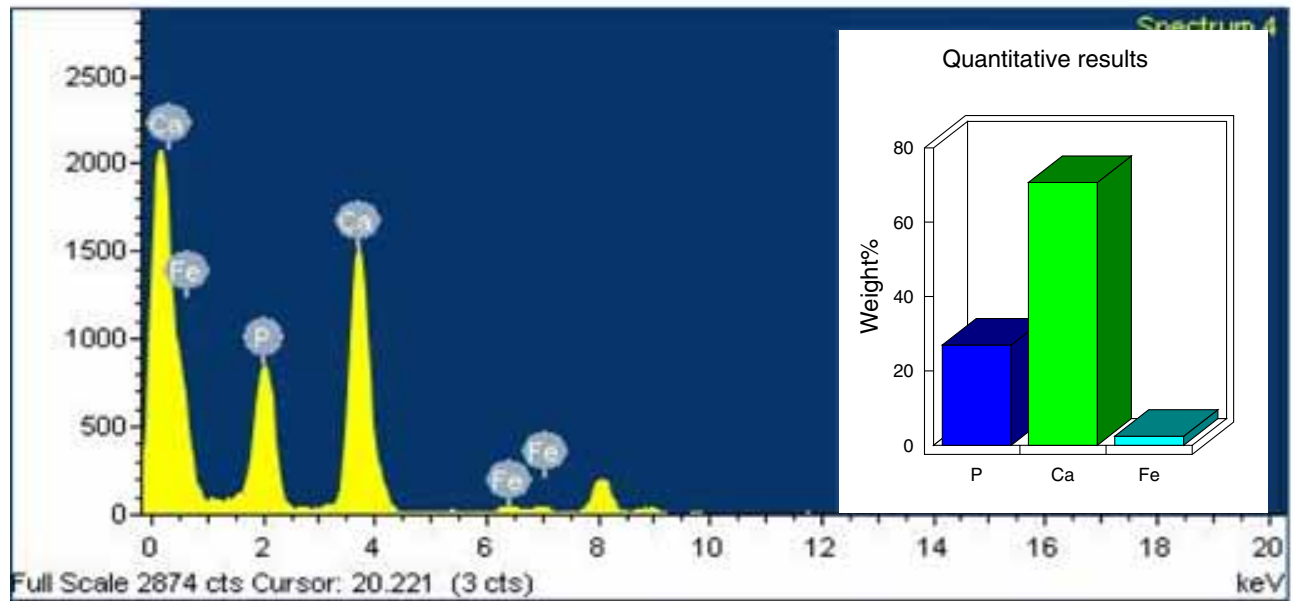

(c)

Figure 11. (a, b) TEM images of HAp nanoparticles coated on iron oxide tubular structure and (c) EDAX.

tubular-like structure can be seen clearly, with the length of $70-80 \mathrm{~nm}$.

3.8c HAp-coated iron oxide tubular structure: The TEM analysis of HAp-coated iron oxide nanotubes templated by kapok nanofibre shows that the tubular-like structure consists of HAp and iron oxide. The further magnification of the surface shows nanotubular-like structure (figure 11). The formed tubular structures have iron oxide core as an inner layer and HAp as an outer layer. These nanotubular composite structures have an inner diameter of $300 \mathrm{~nm}$ and an outer diameter of $500 \mathrm{~nm}$. The SAED pattern shown in figure $2 \mathrm{~b}$ exhibits the presence of $\mathrm{Fe}_{3} \mathrm{O}_{4}$ and HAp structure.

\section{Conclusion}

In conclusion, HAp-coated magnetite tubular structure developed through a simple natural template-mediated method revealed that the obtained nanotubes are composed of HAp and $\mathrm{Fe}_{3} \mathrm{O}_{4}$ (by FE-SEM and TEM analyses). This magnetic tubular structure can be effectively used for magnetic hyperthermia treatment with suitable drug-loading strategy.

\section{Acknowledgements}

We are thankful to the Head of the Department, Dean, Principal and the Management for providing facilities to carry out this research. This work was supported by DST No. SB/S2/CMP-106/2013, New Delhi.

\section{References}

[1] Weibo Cai and Xiaoyuan Chen 2007 Small 31840

[2] Davis M E, Chen Z G and Shin D M 2008 Nat. Rev. Drug Discov. 7771

[3] Zhang L, Gu F X, Chan J M, Wang A Z, Langer R S and Farokhzad O C 2008 Clin. Pharmacol. Ther. 83761

[4] Peer D, Karp J M, Hong S, Farokhzad O C, Margalit R and Langer R 2007 Nat. Nanotechnol. 2751

[5] Gianfranco Baronzio, Gurdev Parmar, Marco Ballerini, Andras Szasz, Miriam Baronzio and Valter Cassutti 2014 J. Integr. Oncol. 3115 
[6] Rudolf Hergt, Silvio Dutz, Robert Müller and Matthias Zeisberger 2006 J. Phys.: Condens. Matter 18 S2919

[7] Sophie Laurent, Silvio Dutz, Urs O Häfeli and Morteza Mahmoudi 2011 Adv. Colloid Interface Sci. 1668

[8] McCarthy J R, Kelly K A, Sun E Y and Weissleder R 2007 Nanomedicine 2153

[9] Ajay Kumar Gupta and Mona Gupta 2005 Biomaterials 26 3995

[10] Nasongkla N, Bey E, Ren J, Ai H, Khemtong C, Guthi J S, Chin S F, Sherry A D, Boothman D A and Gao J 2006 Nano Lett. 62427

[11] Rajendra K Singh, Ahmed M El-Fiqi, Kapil D Patel and Hae-Won Kim 2012 Mater. Lett. 75130

[12] Anee Kuriakose T, Narayana Kalkura S, Palanichamy M, Arivuoli D, Karsten Dierks, Bocelli G and Betzel C $2004 \mathrm{~J}$. Cryst. Growth 263517

[13] María Vallet-Regi and Eduardo Ruiz-Hernández $2011 \mathrm{Adv}$. Mater. 235177

[14] Meenakshi Sundaram N, Girija E K, Ashok M, Yokogawa Y and Kalkura S N 2006 Mater. Lett. 60761
[15] Yujie Xiong, Brian T, Mayers and Younan Xia 2005 Chem. Commun. 405013

[16] Hidenori Nakamura and Yasushi Matsui 1995 J. Am. Chem. Soc. 1172651

[17] Patrick Hoyer 1996 Langmuir 121411

[18] Lin Pu, Ximao Bao, Jianping Zou and Duan Feng 2001 Angew. Chem. Int. Ed $\mathbf{4 0} 1490$

[19] Rao C N R, Govindaraj A, Leonard Deepak F, Gunari N A and Manashi Nath 2001 Appl. Phys. Lett. 781853

[20] Dloczik1 L, Engelhardt R, Ernst K, Fiechter S, Sieber I and Könenkamp R 2001 Appl. Phys. Lett. 783687

[21] John C Hulteen, Kshama B Jirage and Charles R Martin 1998 J. Am. Chem. Soc. 1206603

[22] Tourillon G, Pontonnier L, Levy J P and Langlais V 2000 Electrochem. Solid-State Lett. 320

[23] Balasaheb B Chandanshive, Priyanka Raib, Andre L Rossic, Ovidiu Ersenc and Deepa Khushalan 2013 Mater. Sci. Eng. C 332981

[24] Chang-Woo Lee, Kyoung-No Lee and Jai-Sung Lee 2009 Mater. Lett. 632607 